\title{
Double Chondrocutaneous Composite Free Graft in Nasal Reconstruction. Report of a Case and Technique Description
}

\author{
Luigi Maria Lapalorcia ${ }^{1}$, Fabio Massimo Abenavoli ${ }^{2}$, Marino Cordellini ${ }^{1}$ \\ ${ }^{1}$ Plastic Surgery Department, ASL 1 of Umbria, Città di Castello, Italy \\ ${ }^{2}$ Plastic Surgery Department, San Pietro Hospital, Rome, Italy \\ E-mail: luigi.lapalorcia@gmail.com
}

Received September 15, 2011; revised October 12, 2011; accepted October 30, 2011

\begin{abstract}
Full thickness skin grafts and composite grafts are a workhorse in reconstructive surgery of nose and ear defects whether they are originated from trauma, cancer surgery or burns. The reliability of these grafts has been proved with an established clinical use and morbidity to the donor site is minimal if harvesting and donor site selection if appropriate. Use of double or multiple grafts to reconstruct a complex defect of the nose has not been described and our report is meaningful for the fact that it describes a further use of the surgical concept of grafting.
\end{abstract}

Keywords: Nasal Reconstruction, Composite Graft, Free Chondrocutaneous Graft, Skin Graft, Burns, Cartilage Graft, Donor Site

\section{Introduction}

We present the case of an 11 year old female patient that was involved, 2 years before in a bomb related house fire in a war zone of the world (Figure 1).

The patient presented stable 1 year after an initial reconstructive surgery session.

Function of right eye was jeopardized due to insufficient right upper lid mobility and retraction (vision 3-10).

Diffuse burns to facial soft tissues and neck determined her inability to hyper extend the neck. Retractions to lower lip and upper lip determined severe difficulties when patient was assuming liquid and solid diet.

Scar tissue was universally present from her upper forehead to her upper thorax where evidence of an hair bearing area witnessed a previous full thickness skin graft (FTSG) harvested from her upper right thigh (Figure 2).

Nasal dorsum, scroll and tip (medial and lateral crura) where totally absent as a result of fire. Nasal skin was thin and scarred as a result of the thermal insult.

As demonstrated during a face CT no bone abnormalities or fractures were present. Only a left nasal septal deviation was evident.

Our surgical planning was structured as follows:
- Placement of skin expanders in the upper thoracoclavicular area (in number of $4100 \mathrm{cc}$ ).

- Upper and lower right lid skin grafts to correct ectropion and right upper lid retraction.

- Upper lip debridement and FTSG.

- Lower lip debridement and FTSG.

- Nasal tip reconstruction using double (bilaterally harvested) composite condrocutaneous grafts from the retroauricular concha.

\section{Technique Description of the Latter}

Composite grafts have an established role in reconstruction of full thickness defects of various anatomical structures of the face and body ranging from the auricular region, upper and lower lids, after trauma or oncologic surgery, alar rim, tip and septal defects, and defects of the fingertips [1-8].

Several donor sites in the auricle have been described [9-10] with minimal morbidity and morphologic alteration. No microsurgical anastomosis are normally possible as no named suitable vessels are present and tissue amount to transfer is minimal in size and weight.

Survival of the graft is guaranteed by the vascularity of the dermal component of the skin of the auricle as 


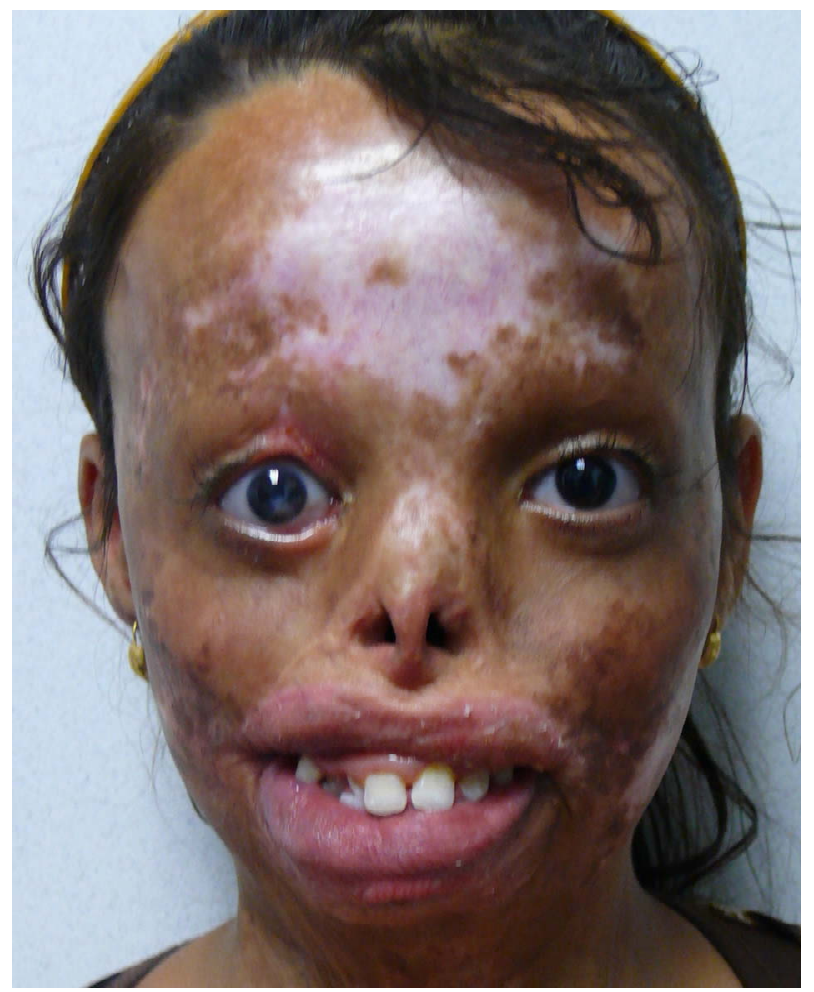

Figure 1. Preoperative status of patient.

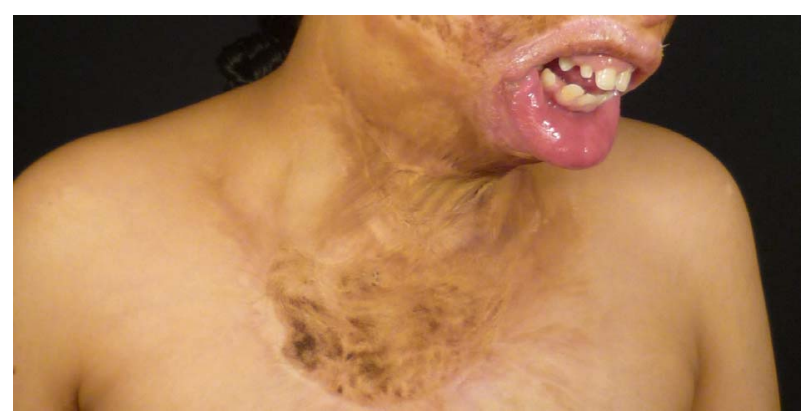

Figure 2. View of the upper thorax with hair bearing area grafted from the upper thigh.

recently described by Tomita et al. [11].

Local pedicled flaps where excluded in this case as the previous burn sequelae had totally jeopardized the dermal vascularization that normally allows survival of facial pedicled flaps.

We opted for bilateral chondrocutaneous grafts. Skin of the posterior aspect of the auricular concha was bilaterally harvested with the perichondrium and cartilagineous component as outlined in the preoperative marking and placed on a recipient bed of appropriate size prepared using sharp dissection in order to minimize trauma to tissues (Figures 3 and $\mathbf{4}$ ).

Fixation of the graft was done with 5-0 vicryl and antibiotic ointment and vaseline gauze was applied with a soft dressing (Figure 5).

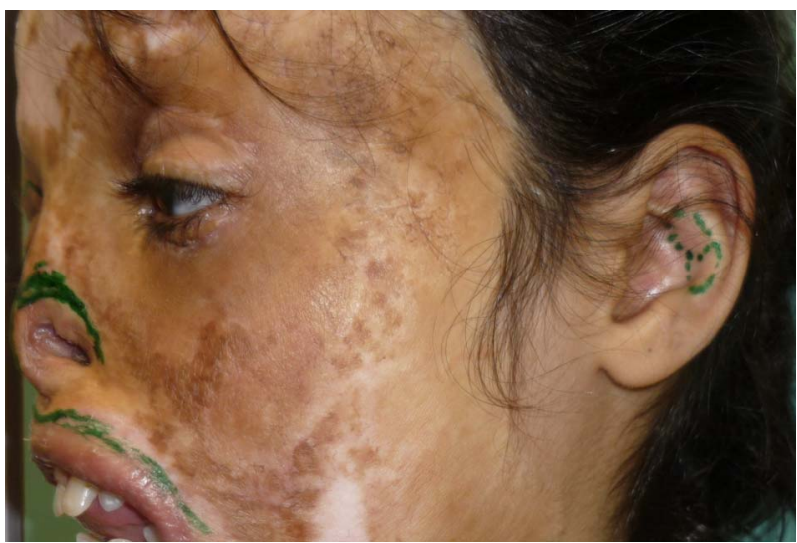

Figure 3. Outline of the cartilaginous component of the composite graft. Attached skin is from the posterior aspect of the auricular concha.

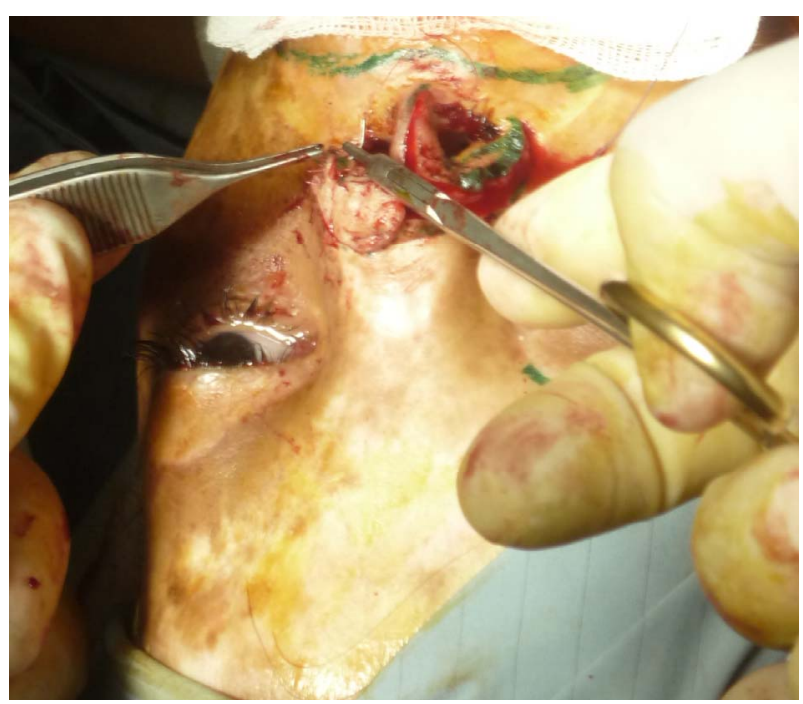

Figure 4. Suturing of the composite graft to the recipient site with vicryl rapide 5.0 .

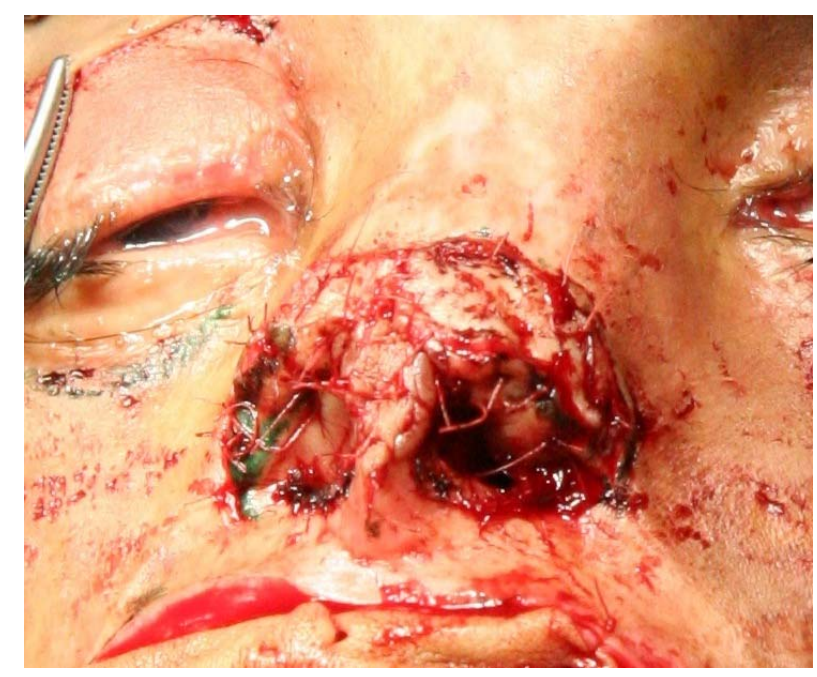

Figure 5. Graft in place. 
Assessment of graft's survival was verified on POD 5.

\section{Discussion}

Use of autologous chondrocutaneous graft from the auricular region has been first described in the fifties by Sathyanarayana Setty Pr et al. [12] in the sixties [13], in the eighties [6,7] and in the nineties in a microvascularized variant described by Pribaz and Tanaka [14,15]. Subsequently several applications have been used in multiple reconstructive settings such as reconstruction of ear defects, alar rim, nasal tip, nasal lower third aesthetic subunits [3-5] with favorable results for patients.

Use of bilateral grafts approached medially to reconstruct a complete dome in a burned patient has not been described and the success of the graft was encouraging for us and aesthetically and functionally effective for the patient.

Minimal morbidity of the donor site for extensive facial grafting was encountered and no complications occurred $[10,11]$.

Nasal inferior cartilaginous components were re-established, nasal valve was reconstructed [16], and inferior and lateral aesthetic units of the nose were restored (Figure 6). Of course patient selection and accurate planning of the operation are mandatory for a favorable outcome and take of the graft. Smoking is contraindi-

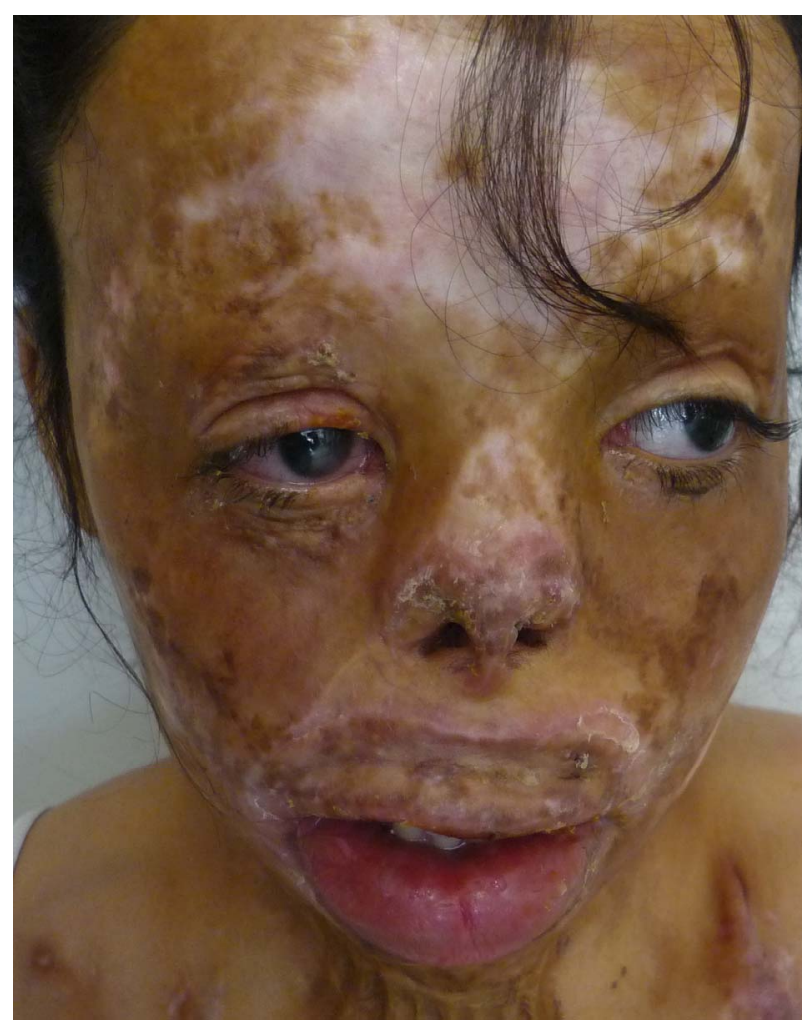

Figure 6. Postoperative status of the patient on POD 60. cated and nutritional status must be assessed. Surgical technique has to be meticulous and follow up of the patient should be very close in order to intervene promptly not only on the grafted area but also on the donor sites to diagnose and treat complications.

On POD day 11 cc of blood was evacuated from the left ear and organized otohematoma was avoided.

\section{Acknowledgements}

Special thanks go to: Mrs Anastasia Iliana Economou for picture editing and language revision.

\section{References}

[1] Y. K. Coban and Y. Geyik, “An Ideal Composite Graft Donor Site for Postburn Alar Rim Deficiencies: Root of Helix," Journal of Craniofacial Surgery, Vol. 21, No. 4, 2010, p. 1246. doi:10.1097/SCS.0b013e3181e431f4

[2] P. D. McCluskey, F. C. Constantine and J. F. Thornton, "Lower Third Nasal Reconstruction: When Is Skin Grafting an Appropriate Option?” Plastic \& Reconstructive Surgery, Vol. 124, No. 3, 2009, pp. 826-835. doi:10.1097/PRS.0b013e3181b03749

[3] S. Riml, H. Wallner, L. Larcher, U. Amann and P. Kompatscher, "Aesthetic Improvements of Skin Grafts in Nasal Tip Reconstruction,” Aesthetic Plastic Surgery, Vol. 25, No. 4, 2010, pp. 475-479.

[4] S. Kobayashi, U. Haramoto and K. Ohmori, "Correction of the Hypoplastic Nasal Ala Using an Auricular Composite Graft,” Annals of Plastic Surgery, Vol. 37, No. 5, 1996, pp. 490-494.

doi:10.1097/00000637-199611000-00006

[5] L. Ohlsén, "Closure of Nasal Septal Perforation with a Cutaneous Flap and a Perichondrocutaneous Graft,” Annals of Plastic Surgery, Vol. 21, No. 3, 1988, pp. 276-288. doi:10.1097/00000637-198809000-00017

[6] J. M. Avelar, J. M. Psillakis and F. Viterbo, "Use of Large Composite Grafts in the Reconstruction of Deformities of the Nose and Ear," British Journal of Plastic Surgery, Vol. 37, No. 1, pp. 55-60. doi:10.1016/0007-1226(84)90043-2

[7] S. H. Lipman and R. J. Roth, "Composite Grafts from Ear Lobes for Reconstruction of Defects in Noses," Journal of Dermatologic Surgery \& Oncology, Vol. 8, No. 2, 1982, pp. 135-137.

[8] D. F. Kalbermatten, M. Haug, R. Wettstein, D. J. Schaefer and Pierer G. "New Posterior Auricular Perichondrial Cutaneous Graft for Stable Reconstruction of Nasal Defects,” Aesthetic Plastic Surgery, Vol. 29, No. 6, 2005, pp. 489-495. doi:10.1007/s00266-005-0069-1

[9] M. D. Haug, U. M. Rieger, P. Witt and W. Gubisch, "Managing the Ear as a Donor Site for Composite Graft in Nasal Reconstruction: Update on Technical Refinements and Donor Site Morbidity in 110 Cases," Annals of Plastic Surgery, Vol. 63, No. 2, 2009, pp. 171-175. 
doi:10.1097/SAP.0b013e318189a9c4

[10] D. J. Singh and S. P. Bartlett, "Aesthetic Management of the Ear as a Donor Site," Plastic \& Reconstructive Surgery, Vol. 120, No. 4, 2007, pp. 899-908.

doi:10.1097/01.prs.0000277659.88395.a5

[11] K. Tomita, K. Hosokawa, K. Yano, A. Takada, T. Kubo and M. Kikuchi, "Dermal Vascularity of the Auricle: Implications for Novel Composite Grafts,” Journal of Plastic, Reconstructive \& Aesthetic Surgery, Vol. 62, No. 12, 2009, pp. 1609-1615. doi:10.1016/j.bjps.2008.06.073

[12] P. R. Sathyanarayana Setty, F. Misquith, Jeevandrakumar, "Plastic Repair of Loss of Ala Nasi with Composite Graft from the Ear," Journal of the Indian Medical Association, Vol. 32, No. 5, 1959, pp. 203-204.

[13] S. Soeda, "Composite Graft from the Earlobe to the
Nose,” Keisei Geka., Vol. 10, No. 2, 1967, pp. 112-119.

[14] J. J. Pribaz and N. Falco, "Nasal Reconstruction with Auricular Microvascular Transplant,” Annals of Plastic Surgery, Vol. 31, No. 4, 1993, pp. 289-297. doi:10.1097/00000637-199310000-00001

[15] Y. Tanaka, S. Tajima, K. Tsujiguchi, E. Fukae and Y. Ohmiya, "Microvascular Reconstruction of Nose and Ear Defects Using Composite Auricular Free Flaps,” Annals of Plastic Surgery, Vol. 31, No. 4, 1993, pp. 298-302. doi:10.1097/00000637-199310000-00002

[16] D. J. Bottini, P. Gentile, A. Arpino, G. Dasero and V. Cervelli, "Reconstruction of the Nasal Valve," Journal of Craniofacial Surgery, Vol. 18, No. 3, 2007, pp. 516-519. doi:10.1097/scs.0b013e318052ff30 